\title{
BANKING SECTOR ORIENTED FINANCIAL INCLUSION IN INDIA: A LONG TERM PERSPECTIVE
}

\author{
Ms. Sana Pathan \\ Dr. Archana Fulwari
}

\begin{abstract}
Financial Inclusion is an emerging concept. The objective of the government behind 100 percent Financial Inclusion is to have inclusive growth in India. Several initiatives have been taken by the Government of India and the Reserve Bank of India to improve access to financial services. To measure the effectiveness of these initiatives there is need to measure the extent of Financial Inclusion. Financial Inclusion can be measured by gauging the progress in access to and usage of a range of products and services of financial institutions over time. The present study sought to propose an index to measure the extent of banking sector oriented Financial Inclusion in India over a period of time rather than a cross-section study which has been the focus of many a studies. The study used more specific indicators of banks-centric financial inclusion dimensions to gauge the long run trend in Financial Inclusion in India. The results indicate that there is much improvement in Financial Inclusion in India since the implementation of financial sector reforms.
\end{abstract}

Key word: Financial Inclusion, Financial Access, Bank Penetration, Financial Inclusion Index

JEL Classification: G20, G21

Financial Inclusion is an emerging concept. It is defined "as the process of ensuring access to financial services and timely and adequate credit where needed by vulnerable group such as weaker and low income groups at an affordable cost" (Rangrajan Committee, 2008). The government aims not only to provide financial access to weaker 


\section{Pathan \& Dr. Archana Fulwari / Page 42-59}

sections but also to provide them at costs lower than that to the privileged groups. Financial Inclusion is important for inclusive growth, financial sector development and economic growth of the country.

Financial access helps improve Financial Inclusion. Access comprises the first and the basic foundation for improvement in Financial Inclusion. The two objectives of India as mentioned in directive policy is growth and social justice which can be fulfilled by having inclusive growth. Financial access can act as a tool to achieve these two objectives by including weaker sections of the society under financial services which will lead to lessening of income inequality and poverty. Major initiatives and approaches have been taken by the Government of India and the Reserve bank of India to improve Financial Inclusion such as self help groups, micro finance, relaxations of 'Know Your Customer' norms, bank led approaches, product based approaches, etc.

To check the effectiveness of these initiatives it is necessary to measure the extent of Financial Inclusion it has resulted into. The Credit Rating Information Services of India Limited (CRISIL) was the first to develop an innovative way to measure Financial Inclusion by proposing an index combining various dimensions of Financial Inclusion. Financial access can be measured in different ways, such as, firstly by measuring the progress in banking sector using variables, such as, bank penetration, bank branch density and ATM density. Secondly, financial access can be measured in terms of access to financial institutions beyond banks such as insurance companies, Micro Finance Institutions (MFls), Non-bank Financial Companies, etc. Use of different specific financial products such as debit cards, credit cards, loans, life insurance and pension schemes are the third alternative measure of access to the financial sector.

The research content on Financial Inclusion is developing over time with more precise measures of access to the financial sector being sought. New measures of financial inclusiveness of the country are being developed. Worldwide the Financial Inclusiveness Index is being used to measure the progress in Financial Inclusion. 
Most studies like Sarma (2008), Sarma and Pais (2008) Goel and Sharma (2017), and Adhikary, Bagli and Dutta (2017) have used similar indicators to compute Financial Inclusion Index for India over different time periods and with varying scope. Sarma (2008) has made country comparison by proposing an Index for Financial Inclusion using three variables namely Banking Penetration, that is, the number of bank accounts per 1000 population, Availability of Financial Services, that is, the number of bank branches and ATMs per 1000 population, and Usage of Financial Services measured by the ratio of the volume of credit and deposit to GDP. The study computes two set of indices, the first set being the index using all three dimensions for 55 countries for the year 2004. By dropping one dimension namely banking penetration the second set computes index for 100 countries for the same year. The results show that Spain ranks first in both the set of indices and India ranks $29^{\text {th }}$ position in three dimensional index with low Financial inclusion. The study concludes that a large number of economies have low levels of Financial Inclusion. Due to lack of data on many aspects of Financial Inclusion like affordability of the financial services, promptness of the services, quality of financial product, etc., have not been studied by the researcher.

Sarma and Pais (2008) extend the enquiry by using the index developed by Sarma (2008) to investigate macro level factors that can be connected with Financial Inclusion. The study also analyzes the relationship between Financial Inclusion Index (FII) and Human Development Index for 49 countries for the year 2004. The result showed India ranking at the $29^{\text {th }}$ position in FII with low level of Financial Inclusion and $42^{\text {nd }}$ in the HDI. By performing three sets of regressions it tries to find out country specific factors that influence the level of Financial Inclusion. These include socio-economic factors, physical infrastructure, and banking sector factors. The study concludes that there is a positive correlation between Financial Inclusion and human development. It points out that the countries with the stronger physical infrastructure have better Financial Inclusion.

Arora (2010) has focused on the extent of financial access in both developed and developing countries. The study computes Financial Access Index (FAI) for 98 developed and developing countries according to the coverage of data and ranks them 


\section{Pathan \& Dr. Archana Fulwari / Page 42-59}

accordingly. The study not only examines financial access both in terms of banking sector as well as non-banking companies. India is found to rank $29^{\text {th }}$ with low level of Financial Inclusion. The study has modified the human development index (HDI) by including financial access as one of its components and terms it as the Economic Development Index (EDI). It ranks the country on the basis of comparisons of EDI and HDI.

State-wise comparison of Financial Inclusion in India are found in Bagli and Dutta (2012) who have examined the relative importance of the indicators of Financial Inclusion and ranked states on the basis of a composite financial index developed using ten variables ranging from population coverage of bank branches, geographical coverage of banks, deposit and credit accounts. Other indicators used by them include per capita deposits and credit, and penetration of credit with reference to net state domestic product. The study has used principal component analysis on select indicators of Financial Inclusion and examines the degree of association between human development and Financial Inclusion. They find that states differ in the level of Financial Inclusion and level of poor information technology was the main cause of financial exclusion. The study concludes that there is a significantly positive relationship between human development and Financial Inclusion. However, it finds no strong relationship found between income and Financial Inclusion.

Another state-wise study of Financial Inclusion is found in Ambarkhane, Singh and Venkataramani (2016). They study the level of Financial Inclusion for 21 states of India. Along with banking services they also take into consideration other financial services like insurance, pension, and the level of financial literacy and remittances. The index is developed by taking into account three dimensions, namely, demand side, supply side and infrastructure. On the supply side, it basically focuses on access to services provided by banks, NBFCs, and insurance companies. The demand side dimensions include usage of services provided by the same institutions. Under infrastructure the study includes variables like irrigation, transport, power, literacy and health. It also 


\section{Pathan \& Dr. Archana Fulwari / Page 42-59}

includes, additionally, drag factors for each state such as population size and law and order situation to construct a Comprehensive Financial Inclusion Index.

Adhikary, Bagli and Dutta (2017) have constructed an index to measure Financial Inclusion in each state of India for the year 2010 using three dimensions, namely, spread, width and depth. The 'spread' dimension includes population and geographical coverage of banks and bank branches. They measure width of the financial inclusion in terms of deposit and credit accounts, while the depth dimensioned is captured in terms of percentage of savings to net state domestic product and percentage of credit outstanding to net state domestic product. All other states come under low financial inclusion level. The study has also examined the role of human development and the effect of self help groups on Financial Inclusion through linear regression model. It concludes that there is a significantly positive impact of human development on Financial Inclusion with more advanced states exhibiting higher level of Financial Inclusion. All three state-wise studies find Goa to rank first with high level of financial inclusion.

Goel and Sharma (2017) have proposed an index for Financial Inclusion (FII) by using several indicators of three dimensions such as Banking Penetration, Availability of Financial Services, and Access to Insurance Services. measured as number of life insurance offices. The study computes FII for the period of twelve years from 20052012. The study shows improvement in India where it ranges from low Financial Inclusion in mid 2000s to high Financial Inclusion in 2014-2015.

Deepti and Subramaniam (2018) have computed multidimensional Financial Inclusion index for five years ranging from 2011-12 to 2015-16, using three dimensions, namely penetration, availability, and usage. The study concludes that there is significant increment in Financial Inclusion due to improvement in the dimensions. It also helps to analyze the problem of Financial Inclusion for policy making. The study suggests that greater improvement in the availability and usage dimensions can help in achieving better Financial Inclusion. 
Singh (2018) has examined the CRISIL 'Inclusix' index. He checks for the validity of the index in successfully measuring Financial Inclusion by particularly focussing on the Jan Dhan Yojana (National Mission on Financial Inclusion). The study states that microfinance institutions and Jan Dhan Yojana have made more improvement in financial access as both pay more attention to weaker sections of the society.

From the review of literature it is clear that there are different dimensions used to compute the Financial Inclusion Index. The present study seeks to construct an index of banking sector oriented Financial Inclusion that draws from the aspects of geographical exclusions from the financial sector. Also, most studies have computed cross-sectional Flls rather than a time series of the FII. Studies that have examined FII over a period of time are found to be limited to less than 12 years, which does not adequately show the changes in Financial Inclusion over time.

Apropos the review of literature, the objective of the paper is to examine the long run trend in the Financial Inclusion Index. It seeks to add to the literature by covering a long period of 27 years. The major highlight of the present study is that all studies so far have adopted a cross sectional approach as they are either comparing countries or states in India for a given year. This makes possible for them to incorporate a wide spectrum of financial inclusion indicators for a carefully selected year(s) for which data is available for all indicators. The basic reason behind this is that long period time series is not available for all parameters or indicators of financial inclusion, simultaneously. Therefore, the present study seeks to focus on a long term perspective by examining the trend in banking sector oriented financial inclusion for a period of 27 years, which is not found in literature so far. The Fll has been constructed on the basis of three dimensions, namely, Banking Penetration, Availability of Banking Services and Usage of Banking services. Various indicators of each of these dimensions have been used. The data on population is collected from World Bank data base. The data on branches, bank accounts and ATM is collected from Reserve Bank of India. The data of credit and 
deposit ratio is taken from the World Bank Data base. The construction of the FII is explained in the following section.

\section{Construction of Financial Inclusion Index}

This section explains the construction of the banks-centric Financial Inclusion Index. The section is divided into five parts. The first part discusses the dimensions and indicators of Financial Inclusion, the second part provides the methodology of constructing the Index, and the third part displays the descriptive statistics related to the indices. The fourth part discusses the computation and analysis.

\section{Dimension and Indicators}

Financial Inclusion Index is a multidimensional measure represented by different indicators. The composition of these indicators makes up the dimensional indices which are then brought together to construct the composite index of Financial Inclusion. The present study uses three dimensions related to banks, namely, Banking Penetration, Availability of Banking Services and Usage of Banking Services represented by modified indicators.

\section{Banking Penetration (BPi)}

Banking penetration seeks to capture how widely banking services have penetrated among its users. In other words, it means making the banking services available to a larger population of the economy. The alternative indicators of bank penetration are represented by BPi.

\section{Availability of Banking Services (Ai)}

Often banks may have penetrated well, covering large percentage of the population, however, the ease with which banking services are available may still be a challenge. It is common knowledge that often in remote areas the closest bank available may be several kilometres away and not easily reachable, discouraging banking habits. The 
Availability indicator seeks to check for the ease with which the banking services are available. Its indicators are represented by Ai.

For representing the availability of banking services, the study draws from aspects of geographical exclusion from formal financial sector, that is, it gives representation to the geographically excluded population by separating the availability measure for urban visa-vis rural population. While rural banking improved on nationalization of banks, over time entry of private and foreign banks has led to change in the banking scenario with greater thrust on profitability. It is common knowledge that urban areas not only have good bank penetration, but are also interspersed with branches of several banks located in close vicinity making availability extremely easy, whereas, in the rural areas bank branches may be located at prohibitive distance. To gauge this, the availability dimension has been computed for rural and urban population separately so as to differentiate between the ease of availability in rural versus urban areas. The greater the availability of bank branches the greater the ease of using banking services.

\section{Usage of Banking Services (Ui)}

This dimension seeks to captures the marginally banked population. These include people who have bank accounts but do not make much use of their accounts. This is because merely having a bank account does not imply effective Financial Inclusion; it is also important that banking services are adequately used as a norm rather than as an exception. To account for usage of banking services, two indicators representing basic banking services - credit and deposit - are used in the construction of the index. Thus usage measures the extent and frequency of use of financial services by customers. The third dimension, usage of banking services, uses volume of deposit plus credit as percentage of GDP as a proxy variable. Table 1 provides the summary of indicators used in the Financial Inclusion Index.

Table 1: Dimensions and Indicators for Financial Inclusion Index

\begin{tabular}{|l|l|}
\hline \multicolumn{1}{|c|}{ Dimensions } & \multicolumn{1}{c|}{ Indicators } \\
\hline \multirow{2}{*}{ 1. Banking Penetration } & No. of deposit accounts per 1000 adults $\left[\mathrm{BP}_{1}\right]$ \\
\cline { 2 - 2 } & No. of credit accounts per 1000 adults $\left[\mathrm{BP}_{2}\right]$ \\
\hline
\end{tabular}


Pathan \& Dr. Archana Fulwari / Page 42-59

\begin{tabular}{|ll|l|}
\hline & No. of branches per 100,000 adults $\left[\mathrm{BP}_{3}\right]$ \\
\hline 2. & Availability of Banking & No. of branches per 100,000 rural population \\
\multirow{3}{*}{ Services } & {$\left[\mathrm{A}_{1}\right]$} \\
\cline { 3 - 3 } & $\begin{array}{l}\text { No. of branches per 100,000 urban population } \\
{\left[\mathrm{A}_{2}\right]}\end{array}$ \\
\hline 3. Usage of Banking Services & $\begin{array}{l}\text { Volume of deposit plus credit ratio as \% of GDP } \\
{\left[\mathrm{U}_{1}\right]}\end{array}$ \\
\hline
\end{tabular}

\section{Methodology}

The present study adopts a multidimensional approach to the construction of the bankscentric FII. The study uses the methodology used by UNDP to construct the Human development Index (HDI) with appropriate modifications. The construction of index is described in three steps as follows.

\section{Step 1: Normalisation of Dimensions}

The variables used in the index have different units of parameters and therefore cannot be directly aggregated to arrive at a composite index. To construct the proposed index firstly the dimensional index for each dimension is computed. The dimensional indices are calculated by normalising each dimension. This is done as shown in formula (1). The normalised value thus becomes free of the unit of measurement and can directly be used for further computation.

$d_{i}$ $=\quad \frac{A_{i-m_{i}}}{M_{i-m_{i}}}$

where, $d_{i}=$ Dimensional index of $i^{\text {th }}$ dimension $A_{i}=$ Actual value of dimension $i$

$\mathrm{m}_{\mathrm{i}}=$ minimum value of $\mathrm{i}^{\text {th }}$ dimension

$\mathrm{M}_{\mathrm{i}}=$ maximum value of $\mathrm{i}^{\text {th }}$ dimension

Normalisation will transform the original values into values between 0 to 1 , such that, 0 $\leq \mathrm{d}_{\mathrm{i}} \geq 1$ where 0 represents the worst situation and 1 represent the highest achievement. It is not easy here to put absolute upper limits for any dimension in the 
case of Financial Inclusion as in the case of levels of literacy or life expectancy. This is because it is also not possible to assign a definite goal post to the dimension as doing so would be limiting the achievements of the dimensions. So here the actual observed values for both minimum and maximum have been used. The year with the minimum value will have dimensional index as 0 and the year with the maximum value will have 1 as the dimensional index. The Financial Inclusion index in this sense is dynamic as the value for minimum and maximum can change according to the period of study, type of study like state comparison or country comparison, and according to the change in number of countries or states including in the study.

\section{Step 2: Averaging all the Variables}

After normalising the value for each indicator, all indicators of each dimension are averaged to compute the composite dimensional index by using formula (2).

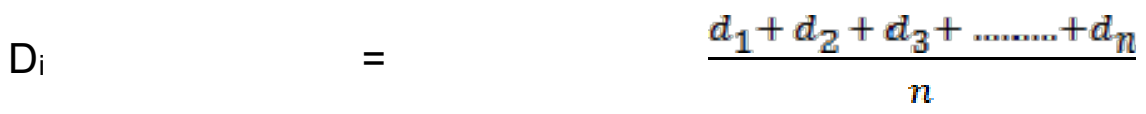

\section{Step 3: Computation of Index}

In the computation of the index equal weight has been assigned to each dimension as all are considered equally important. The present study departs from the computation methodology used by the UNDP. For computing HDI the UNDP uses simple geometric mean which does not satisfy all properties of an index, collectively called NAMPUS (Normalisation Anonymity Monotony Proximity Uniformity Signalling). The most important criticism of the UNDP method is the assumption of the existence of perfect substitutability, that is, an increase in the value of one dimension easily compensates for the decrease in the values of other dimensions, thereby veiling the true picture. In other words, all dimensions are dependent on each other. To avoid this lacuna, the present index uses the Euclidean distance method. It involves subtracting each dimensional index from unity before squaring it up. Similarly, in the final step the derived value is also deducted from unity as follows: 


$$
\mathrm{FII}=1-\sqrt{\frac{\left(1-B P_{i}\right)^{2}+\left(1-A_{i}\right)^{2}+\left(1-U_{i}\right)^{2}}{3}}
$$

The distance based method is free from the shortcomings of perfect substitutability; here all the dimensions are independent of each other. The aggregation does not compensate the poor performance of one dimension with the better performance of another dimension and it satisfies all the properties of an index (NAMPUS).

\section{Descriptive Statistics}

Table 2 shows the descriptive statistics, representing critical values for each of the indicators of different dimensions included in the calculation of the bank-centric FII.

The first indicator of Banking Penetration is bank deposit accounts per 1000 adults whose minimum is 598.57 and maximum is 1881.57 , which means deposits accounts varies very widely between the years 1990 and 2017. It shows that there is much improvement over the years and on an average each person has 0.826 deposit accounts, that is, 826 per 1000 persons. Approximately, there is $44 \%$ variation in data of BP1 which means that the data is not very homogenous or consistent. The second indicator - credit accounts per 1000 adults - has a minimum value of 74.21 and maximum of 177.57 with an average of 0.113 credit accounts per person or 113 credit accounts per 1000 persons. Credit accounts have a coefficient of variation of 26 percent which is relatively consistent compared to deposit accounts. Likewise, other values given in the table may be interpreted.

Table 2: Descriptive Statistics of the Dimensions of Financial Inclusion Index

\begin{tabular}{|l|c|c|c|}
\hline \multicolumn{4}{|c|}{ 1. Banking Penetration } \\
\hline Indicators & $\mathbf{B P}_{\mathbf{1}}$ & $\mathbf{B P}_{\mathbf{2}}$ & $\mathbf{B P}_{\mathbf{3}}$ \\
\hline Min & 598.57 & 74.21 & 8.98 \\
\hline Max & 1881.57 & 177.57 & 14.44 \\
\hline Mean & 826.83 & 113.30 & 10.67 \\
\hline $\begin{array}{l}\text { Standard } \\
\text { deviation }\end{array}$ & 365.40 & 30.09 & 1.56 \\
\hline CV & 44.19 & 26.56 & 14.66 \\
\hline No. of years & 28 & 28 & 28 \\
\hline
\end{tabular}


Pathan \& Dr. Archana Fulwari / Page 42-59

\begin{tabular}{|c|c|c|}
\hline \multicolumn{3}{|c|}{ 2. Availability } \\
\hline Indicators & $\mathbf{A}_{1}$ & $\mathbf{A}_{2}$ \\
\hline Min & 3.66 & 11.19 \\
\hline Max & 5.66 & 20.42 \\
\hline Mean & 4.50 & 13.40 \\
\hline $\begin{array}{l}\text { Standard } \\
\text { deviation }\end{array}$ & 0.63 & 2.87 \\
\hline $\mathrm{CV}$ & 14.05 & 21.42 \\
\hline No. of years & 28 & 28 \\
\hline \multicolumn{3}{|c|}{ 3. Usage (Indicator: $U_{1}$ ) } \\
\hline Min & \multicolumn{2}{|c|}{75.75} \\
\hline Max & \multicolumn{2}{|c|}{141.56} \\
\hline Mean & \multicolumn{2}{|c|}{108.02} \\
\hline $\begin{array}{l}\text { Standard } \\
\text { deviation }\end{array}$ & \multicolumn{2}{|c|}{24.92} \\
\hline $\mathrm{CV}$ & \multicolumn{2}{|c|}{23.07} \\
\hline No. of years & \multicolumn{2}{|c|}{28} \\
\hline
\end{tabular}

It is significant to note that the critical values of availability of banking services among the urban population are about three to four times greater than those for the rural population. The mean availability of banking services to urban population is more than three times the mean availability to rural population. The modification carried out in the present work of differentiating between the ease of availability of banking services in rural vis-a-vis urban region clearly serves the rationale behind doing so. In absence of such bifurcation, the vast gap between rural-urban populations would get disguised. Particularly, since last couple of years there has been a trend among banks to open branches at several locations in a given urban area while closing down several branches in the rural areas.

\section{Analysis and Interpretation}

Fig. 1 shows the trends in the three dimensional indices as well as the final index, that is, the banking sector oriented Financial Inclusion Index. The first dimension, Banking Penetration, has particularly picked up pace since 2004. Among the indicators of Banking Penetration, the deposit accounts exhibited much rapid improvement from 
2012 as the government introduced Basic Saving Bank Deposit accounts which provide basic banking services at very minimum cost. After the launch of the Pradhan Mantri Jan Dhan Yojana the growth rate in deposit accounts is found to have accelerated. Credit accounts too picked up pace in the early 2000s leading to rise in Banking Penetration.

Fig. 1 Dimensional Index and Banking Sector oriented Financial Inclusion Index

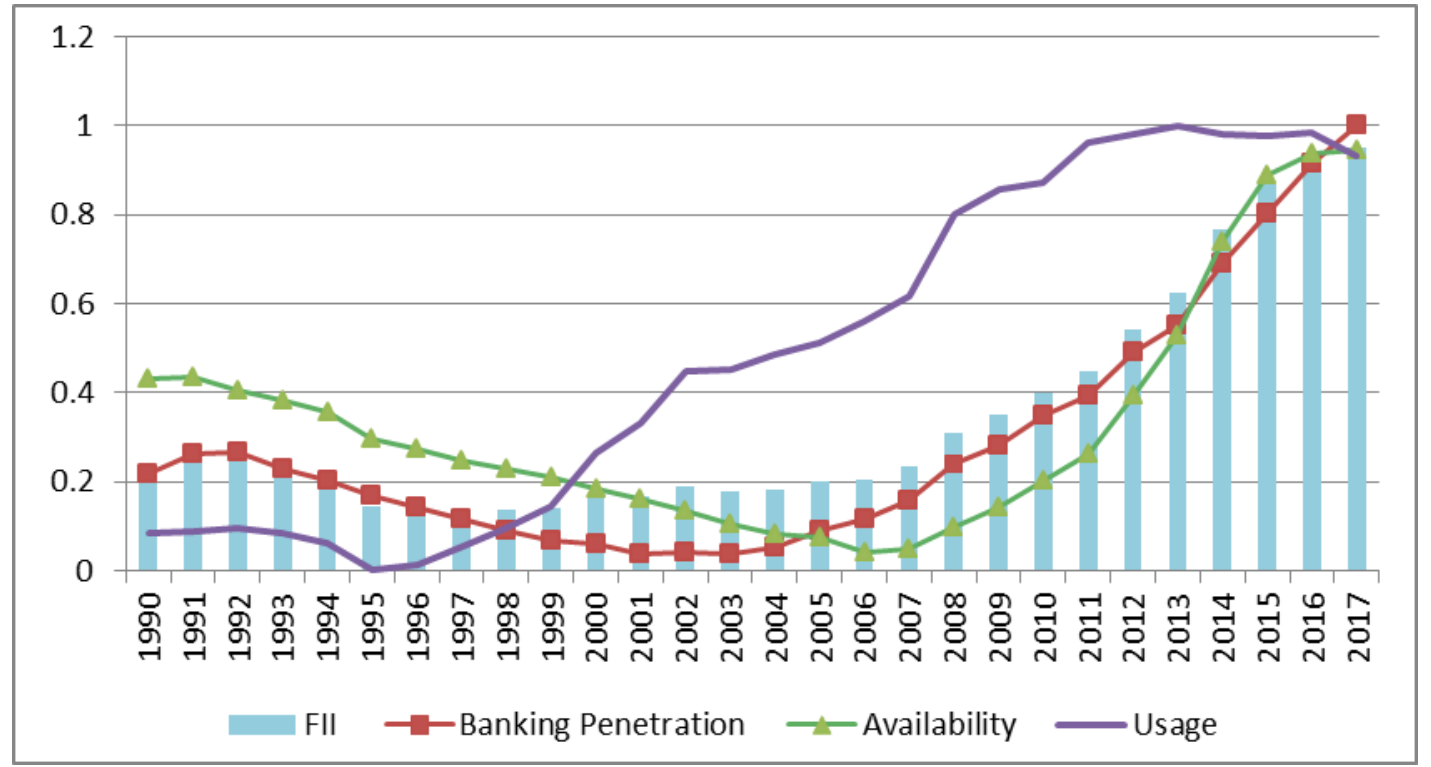

Source: Authors' computations based on data sourced from RBI Publications and World Bank Database

It may be noted that the early 2000s have been the most vibrant period for the Indian economy, reaping the benefits of the economic reforms introduced gradually in the previous decade. The banking sector too experienced heightened level of competition with the aggressive entry and functioning of the private banks. Also, bank penetration being the base level dimension, it exhibits an upward trend much earlier than the other two dimensions. The third dimensional index, Usage of Banking Services shows consistent improvement over the years.

The bars in Fig. 1 indicate the composite index 'FIl'. From the year 2003 onwards there is a gradual but continuous increase in the banks-centric Fll riding on the sharper rise in banking penetration and availability dimensions around the same period. The 2017 value shows the highest level of Financial Inclusion because it exhibited the maximum 
value of almost all the indicators. Between the years 1990 to 2007 there is found to be low Financial Inclusion, from 2008 to 2012 there is medium Financial Inclusion, whereas from 2013 onwards Financial Inclusion has reached high level as per the categories described in Table 3.

Table 3: Interpretation of the Index

\begin{tabular}{|c|c|}
\hline Value of Index & Level of Financial Inclusion \\
\hline $0.6 \leq F I I \geq 1$ & High \\
\hline $0.3 \leq F H \geq 0.6$ & Medium \\
\hline $0 \leq F I I \geq 0.3$ & Low \\
\hline
\end{tabular}

Source: Values and corresponding Levels as assumed by authors

Fig. 2 Rural-Urban Availability Index

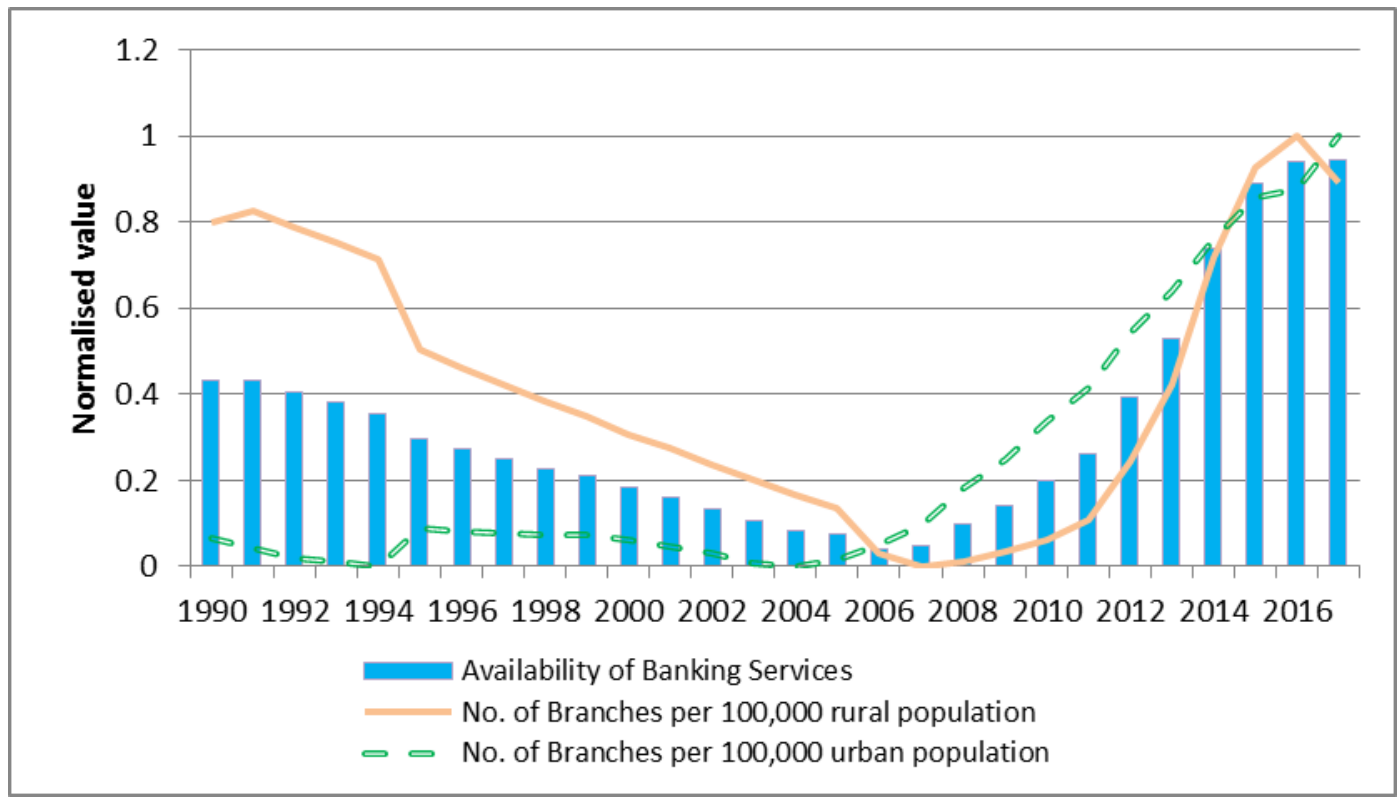

Source: Authors' computations based on data sourced from RBI Publications and World Bank Database

The dimensional index of Availability of Banking Services uses two indicators, first, the distribution of branches among the rural population and second, distribution of branches among the urban population. A very interesting picture emerges when the availability of banking services is compared between rural and urban population as depicted in Fig. 2. It may be observed that availability was better among the rural population up to the mid2000s. This may be attributed to the legacy of focus on rural banking by the public 
sector banks post nationalization of banks. However, increased level of competition in the banking sector has led to an urban bias as banks sought to protect shareholder value. The distribution of bank branches among the urban population shows increase from 2004 onwards, and 2006 onwards the availability of branches among urban population exceeds that of the rural population. Over all there has been a significant increase in the dimensional index of Availability of Banking Services.

The improvement in the banks-centric FIl over the 27-year period is quite dramatic as can be gauged from Table 4. The increase in Financial Inclusion has accelerated along with the vibrancy in the banking sector in India. Very interesting picture emerges when the growth in Financial Inclusion is examined over different time periods. The CAGR of the bank-centric FII has changed from negative to positive in the first decade, and to higher rates for the second decade and for the seven-year period from 2010 to 2017. The faster pace of growth in the FIl may be attributed to the 'JAM' trinity of 'Jan DhanAadhaar-Mobile' (the linking of bank accounts, unique identification number and mobile phone number) used by the government for Direct Benefit Transfer. This has led to more people getting covered by the banking sector. Also, other initiatives of the government such as MNREGA, Kisan (Farmers) Credit Cards, Kisan Bima Yojana (Farmers' Pension Scheme), etc., have been effective in bringing the previously excluded people within the formal banking sector. Another significant observation emerges when the period is divided into 1990 to 2003 and 2003 to 2017, wherein, the first period is characterized by FII fluctuating between 0.13 and 0.25 , and the second period shows continuous growth in FII from 0.18 to 0.95 . The CAGR for the two periods bring forth this contrast in term of $-2.05 \%$ to $12.74 \%$ respectively. The periodic analysis of FII highlights the robust improvement in banking sector oriented Financial Inclusion in India in the post reforms period.

Table 4: Growth in FII

\begin{tabular}{|c|c|}
\hline Period & Compound Annual Growth Rate (\%) \\
\hline $1990-2000$ & -3.31 \\
\hline $2000-2010$ & 9.24 \\
\hline $2010-2017$ & 13.11 \\
\hline $1990-2017$ & 5.36 \\
\hline
\end{tabular}




\section{Pathan \& Dr. Archana Fulwari / Page 42-59}

\begin{tabular}{|c|c|}
\hline $1990-2003$ & -2.05 \\
\hline $2003-2017$ & 12.74 \\
\hline
\end{tabular}

Source: Authors' computations

The banks-centric Financial Inclusion Index of India shows an overall improvement throughout the years. However, it may be noted that inclusion in formal financial sector has many more dimensions beyond the banking sector and must include services of other financial institutions such as insurance companies, mutual funds, stock markets, etc., to represent a more sophisticated level of financial inclusion. However, more sophisticated variables have not been incorporated in the present study as time series data for long period is not available for all the variables. Also, given the fact that there have been a large number of unbanked adults in India, the present paper has focussed on improvement in bank related dimensions of financial inclusion. It may also be noted that although the value of FII has reached close to Unity, it does not imply full financial inclusion but rather a comparison with the maximum value of a given dimension within the period of study. Notwithstanding the definite improvement in the time series of banking sector oriented Financial Inclusion Index in India, it does not suggest whether the level of Financial Inclusion attained is reasonably good. That is possible only when country comparisons are done. There is a long way for India to go before it can have a wider and deeper Financial Inclusion. 


\section{Works Cited}

Ambarkhane, D., Singh,A. S. and Venkataramani, B. (2016). Measuring Financial Inclusion of Indian States. International Journal of Rural Management, 12(1) 72-100, https://DOI: 10.2139/ssrn.2485776

Arora, R. U. (2014). Measuring Financial Access. Griffith University, Economics and Business Statistics, Working Paper Series, Vol.7, https://EconPapers.repec.org/RePEc:gri:epaper:economics:201007

Bagli, S., \& Dutta, P. (2012). A Study of Financial Inclusion in India. Radix International Journal of Economics \& Business Management, 1(8)

Bagli, S., Adhikary, M., and Dutta, P. (2013). An Insight into the Financial Inclusion of the States in India. Journal of Social and Economic Development, 15(1): 50-66

Deepti, N. S., \& Vaidhyasubramaniam, S. (2018). Measure of Index on Financial Inclusion in India. International Journal of Pure and Applied Mathematics, 119(10): 1447-1454

url: http://www.ijpam.eu

Goel, S., Sharma, R. (2017). Developing a Financial Inclusion Index for India. Procedia Computer Science, 122 (2017): 949- 956. https://doi.org/10.1016/j.procs.2017.11.459 Sarma, M. (2008). Index of Financial Inclusion. International Council for Research on International Economic Relations, Working Paper No. 215

Sarma, M., \& Pais, J. (2008). Financial Inclusion and Development: A Cross Country Analysis. Journal of International Development, 23(5): 613- 628

https://doi.org/10.1002/jid.1698

Singh, M. (2018). Study of CRISIL-Inclusix as an Index of Financial Inclusion. International Journal of Management Humanities and Social Sciences, Jan-June 2018, 3(1)

\section{Ms. Sana Pathan \\ Research Scholar, Department of Business Economics, Faculty of Commerce,} The Maharaja Sayajirao University of Baroda, Vadodara E-mail: sana.pathan-be@msubaroda.ac.in 
\&

\author{
Dr. Archana Fulwari \\ Assistant Professor, \\ Department of Business Economics, \\ Faculty of Commerce,
} The Maharaja Sayajirao University of Baroda, Vadodara.

E-mail: archanafulwari@gmail.com 